\title{
BEHAVIOR OF RC HOLLOW BEAM UNDER PURE CYCLIC TORSION
}

\author{
Gajipara J M ${ }^{\mathbf{1}}$, Patel P.V ${ }^{2}$, Raiyani S.D ${ }^{\mathbf{3}}$ \\ ${ }^{l}$ Post Graduate Student, Civil Engineering Department, Institute of Technology, Nirma University, Ahmedabad, \\ Gujarat, India. \\ ${ }^{2}$ Professor, Civil Engineering Department, Institute of Technology, Nirma University, Ahmedabad, Gujarat, India. \\ ${ }^{3}$ Assistant Professor, Civil Engineering Department, Institute of Technology, Nirma University, Ahmedabad, Gujarat, \\ India.
}

\begin{abstract}
Twisting Moment in the member of the skeletal structure due to wind, seismic and other lateral loads are invariably repetitive and cyclic in nature. The reinforced concrete $(R C)$ beam have been found deficient in torsional shear capacity and the behavior of $R C$ beam under torsion is still a topic of research in structural engineering. This paper attempts to evaluate the effect of main reinforcement and shear reinforcement on the behavior of RC hollow beam under pure cyclic torsion and also studied the crack pattern. In present experimental study total 12 RC hollow beams were casted with different amount of longitudinal and shear reinforcement and tested under pure cyclic torsion. The parameters studied were cracking torque, angle of twist, energy dissipation, crack pattern and failure mode. It has been found that in pre cracking mode, reinforcement are ineffective for resisting the torsion moment but in post cracking mode all the torsional moment are resisted by the main rein-forcement. It was overserved that longitudinal reinforcement increase the torsional flexibility of beam, for the same amount of transverse reinforcement. It was also found from the experiment that optimum spacing of transverse reinforcement is equally important parameter while designing for the torsional reinforcement.
\end{abstract}

Keywords: Torsion, RC Hollow beam, cyclic loading, energy dissipation $* * *$

\section{INTRODUCTION}

Beams are transverse members which supports the load through bending and shear. However in some cases torsion moment is likely to be generated, like twisting moment produced by the vertical loads on the spandrel beams, curved beams which are often used in structure. In these cases structural response mainly governed by the torsional shear stresses.

Now a day, due to the architectural requirements hollow RC beams is becoming popular in practice. Due to wind, earthquake and other manmade activity cyclic torsion on the structural member imparted and the RC elements are vulnerable in these loading condition. Huge research is going on for torsional behaviour of RC beams. Different theories for torsion in hollow beams like hollow tube analogy, membrane shear methods for predicting the ultimate torsional strength of RC hollow beam were reviewed with experiment results and it was found to be in good agreement [1]. Researchers have pro-posed various simple non-iterative models for predicting torsional behaviour of RC beams and which gives good agreement to the ACI, CSA and experimental studies with effect of aspect ratio and con-crete crushing [2]. For retrofitting of $\mathrm{T}$ and $\mathrm{L}$ beams anchored inclined U-jacket CFRP is more effec-tive than vertical U-jacket CFRP [3]. Use of continuous spiral reinforcement in reinforced concrete beam provides enhanced torsion capacity and improved post peak performance compared to equal quality and quantity of commonly used stirrups [4]. To enhance the torsional strength, torsional flexi-bility and post cracking behaviour of RC solid beams GFRP and CFRP is good alternative to conven-tional steel plates and retrofitting technique under pure torsion and bending and under pure torsion [5]. Addition of steel fibres in concrete helps in reducing the crack width but increases the amount of micro cracks and good torsional strength of RC beam [6]. High strength concrete exhibits fragile fail-ure and use of high strength concrete does not make huge difference compared to normal concrete but affects only cracking torque and crack pattern strongly depends on amount of total reinforcement ratio [7]. The static torsional behaviour of the beam is influenced if the prior application of cyclic torque with peak torque higher than the static cracking torque [8].

As concrete is brittle in nature, torsion causes crushing of concrete sometimes it leads to sudden fail-ure of structure. Until now various theories are proposed by different researchers for prediction of the torsional strength of reinforced concrete beam. In real the overall behaviour of the reinforced concrete beam under torsion is very complex and no concrete theory is there for predicting the overall behav-iour of the reinforced concrete hollow beam under pure cyclic torsional moments.

The primary objective of the current study is to check experimentally the different parameters which affects the design and behaviour of RC Hollow beam under pure cyclic torsion and observe the effect of main reinforcement in torsional behaviour of beam. 
To achieve above objectives, author casted and tested 6 hollow beams having same size $(150 \mathrm{~mm}$ x $150 \mathrm{~mm}$ x 1500 $\mathrm{mm}$ ) with longitudinal reinforcement bar diameter varies from $8 \mathrm{~mm}$ to $12 \mathrm{~mm}$ and keeping constant transverse reinforcement of $8 \mathrm{~mm}$ diameter with spacing of $100 \mathrm{~mm}$ and $150 \mathrm{~mm}$. Studied parameter are cracking torque, angle of twist, energy dissipation, crack pattern and failure mode of RC Hollow beam under pure cyclic torsion.

\section{EXPERIMENTAL PROGRAMME}

\subsection{Material and Beam Specification}

To understand the behaviour of hollow RC beam under pure cyclic torsion total six beams were casted and tested under pure cyclic torsion using the Torsion Frame. To create hollow section in the beam PVC pipe was inserted at the time of the casting on the centre line of section and supported on the hollow ply wood side panels in the formwork. The beam was cured with jute bags for 28 days and then tasted under pure cyclic torsion. Reinforcement details are shown below in Table 1 of test beams. All beams having same grade of cocrete having chractaristic compressive strength after 28 days as $25 \mathrm{~N} / \mathrm{mm}^{2}$. Stirrups in all beams are of same $8-\mathrm{mm}$ diameter with yield strength of $415 \mathrm{~N} / \mathrm{mm}^{2}$. w/c ration was 0.45 and OPC grade 53 cement was used in casting. Concrete mix praportion was 1:1.68:2.7
(Cement: Fine Agreegate: Coares agreegate) as per IS:10262 $-2009$.

Notation for the beam is given as B for beam, and the digits shown after L is diameter of longitudinal steel, S-stirrup spacing. For example BL8S100 means beam having $8 \mathrm{~mm}$ longitudinal steel and stir-rups @ $100 \mathrm{~mm}$ spacing. The details of beam are shown in Table1:

Table 1: Test Beam specification

\begin{tabular}{|l|l|l|c|}
\hline \multicolumn{1}{|c|}{ Beam } & $\begin{array}{c}\text { Longitu- } \\
\text { dinal Steel }\end{array}$ & \multicolumn{1}{|c|}{$\begin{array}{c}\text { Stirrups } \\
\text { Spacing }\end{array}$} & $\begin{array}{c}\text { No. of } \\
\text { Speci- } \\
\text { men }\end{array}$ \\
\hline BL8S100 & $4-8 \mathrm{~mm}$ & $100 \mathrm{~mm}$ & 2 \\
\hline BL10S100 & $4-10 \mathrm{~mm}$ & $100 \mathrm{~mm}$ & 2 \\
\hline BL12S100 & $4-12 \mathrm{~mm}$ & $100 \mathrm{~mm}$ & 2 \\
\hline BL8S150 & $4-8 \mathrm{~mm}$ & $150 \mathrm{~mm}$ & 2 \\
\hline BL10S150 & $4-10 \mathrm{~mm}$ & $150 \mathrm{~mm}$ & 2 \\
\hline BL12S150 & $4-12 \mathrm{~mm}$ & $150 \mathrm{~mm}$ & 2 \\
\hline \multicolumn{3}{|c|}{ Total } & 12 \\
\hline
\end{tabular}

\subsection{Test Procedure}
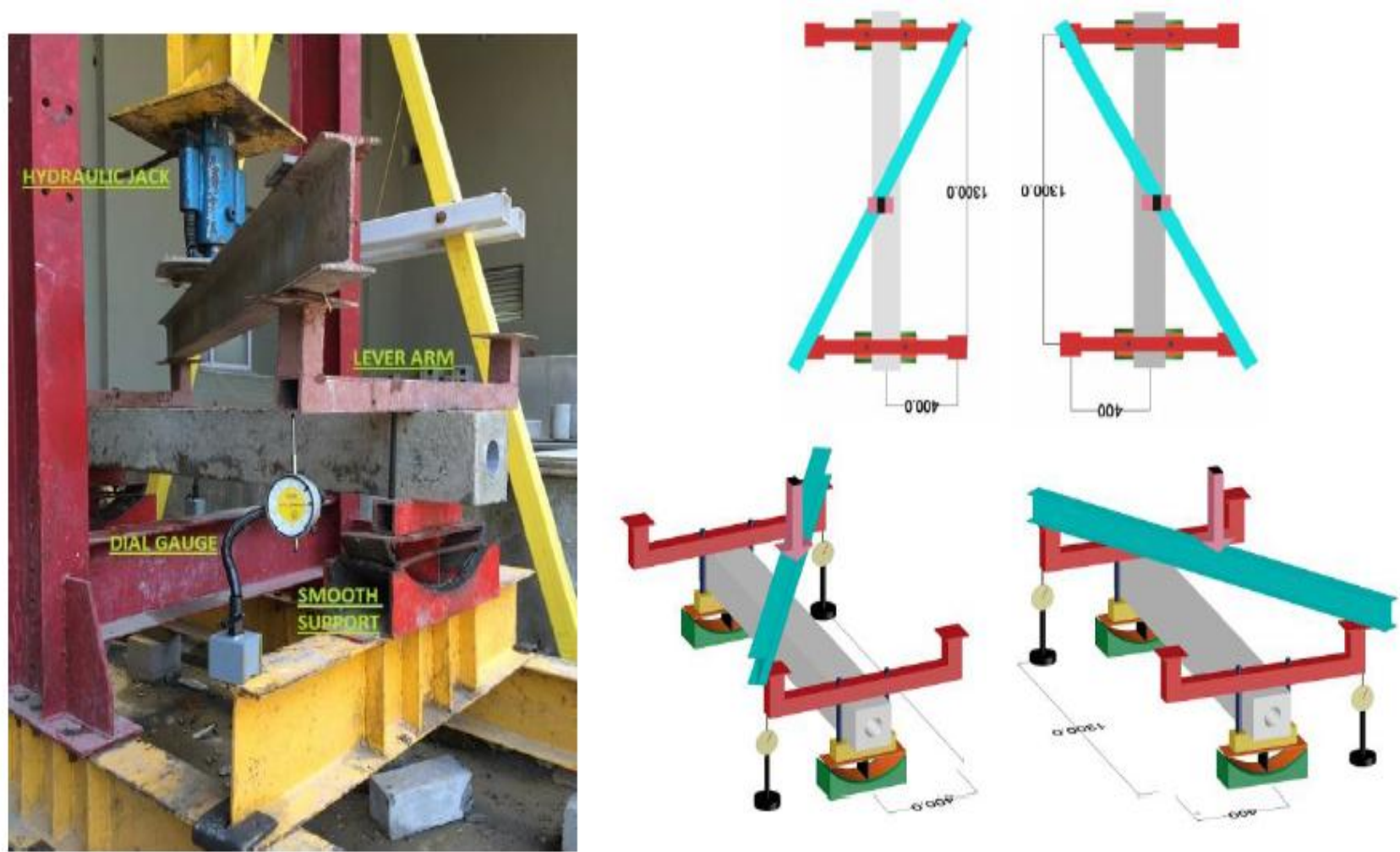

Fig 1: Test Setup

To apply pure cyclic torsion the Torsion loading frame as shown in Figure. 1 is used and spreader beam is used to transfer the load from Hydraulic Jack to the lever arm.
Hydraulic Jack of $250 \mathrm{kN}$ ca-pacity was used to apply load. The lever arm was of length $400 \mathrm{~mm}$ and the beam was rested on the smooth curved support which is free to slide. 
RC beam was held in the position with help of bolts to the support and load was applied with Jack. Two Dial gauges were used to measure the deflection of the lever arm and from that rotation was calculated using trigonometry. Cyclic loading was applied as $6 \mathrm{kN}, 12 \mathrm{kN}, 18 \mathrm{kN}$ cycle and so on. In each load cycle the reading were taken from both loading and unloading process. Then the spreader beam was changed on other end of lever arm and again the same cycle was repeated. This process was repeated until the beam is failed under pure torsion. To calculate torsion on the beam, on each lever arm half of load coming from the jack plus half of the load of spreader beam. Weight of the spreader beam was $0.2 \mathrm{kN}$ and if the total load coming from hydraulic jack is $(P)$ then the torque $(T)$ applied to the beam will be,

$$
T=\left(\frac{P}{2}+0.1\right) \times 0.4 k N m
$$

Let us say the lever arm be 'a' and the vertical displacement in dial gauge be ' $y$ ' then from the geome-try the angle of rotation at one end will be,

\subsection{Parametric Study}

$$
\Theta=\tan ^{-1}\left(\frac{y}{a}\right)
$$

As in the actual experiment to achieve symmetry of loading, two dial gauges were placed at each end of beam. To achieve total angle of twist both the results of angle of twist of each end were summed up.

\section{RESULT AND DISCUSSION}

The test result of beams are detailed for each category of beam and subsequent observations of crack-ing torque, maximum twist and crack pattern are narrated during test. Comparative study of different parameters like cracking torque, no. of cycles that beam has undergone before ultimate failure, energy dissipation during cyclic loading, and angle of twist in each cycle for different category of beam are presented below. It was observed that for same longitudinal steel and different stirrup spacing the no. of load cycle for pure torsion is same. As the amount of longitudinal steel increase the no. of load cy-cle increases.

\section{Cracking Torque}

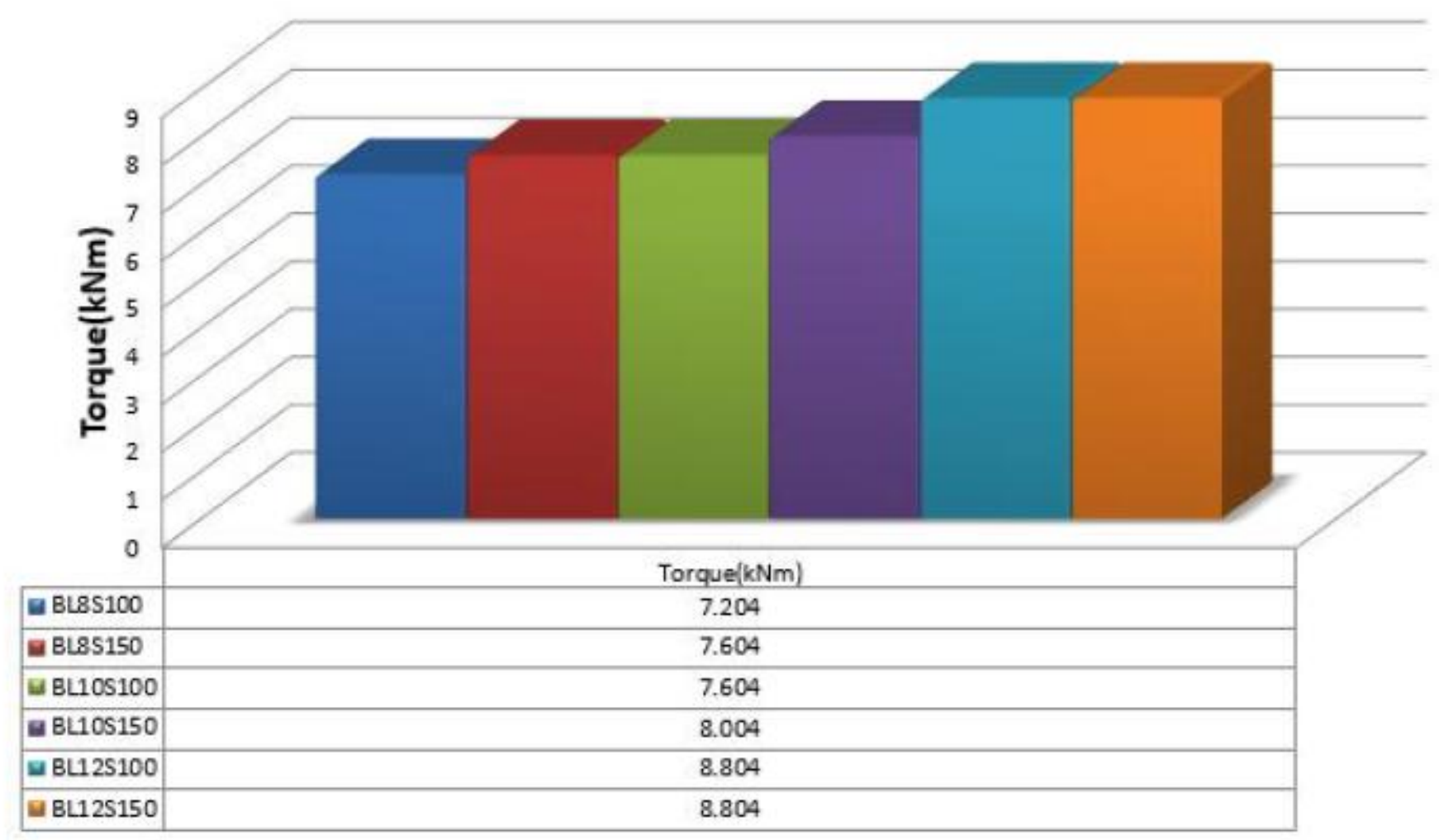

Fig 2: Specimen v/s Cracking Torque 


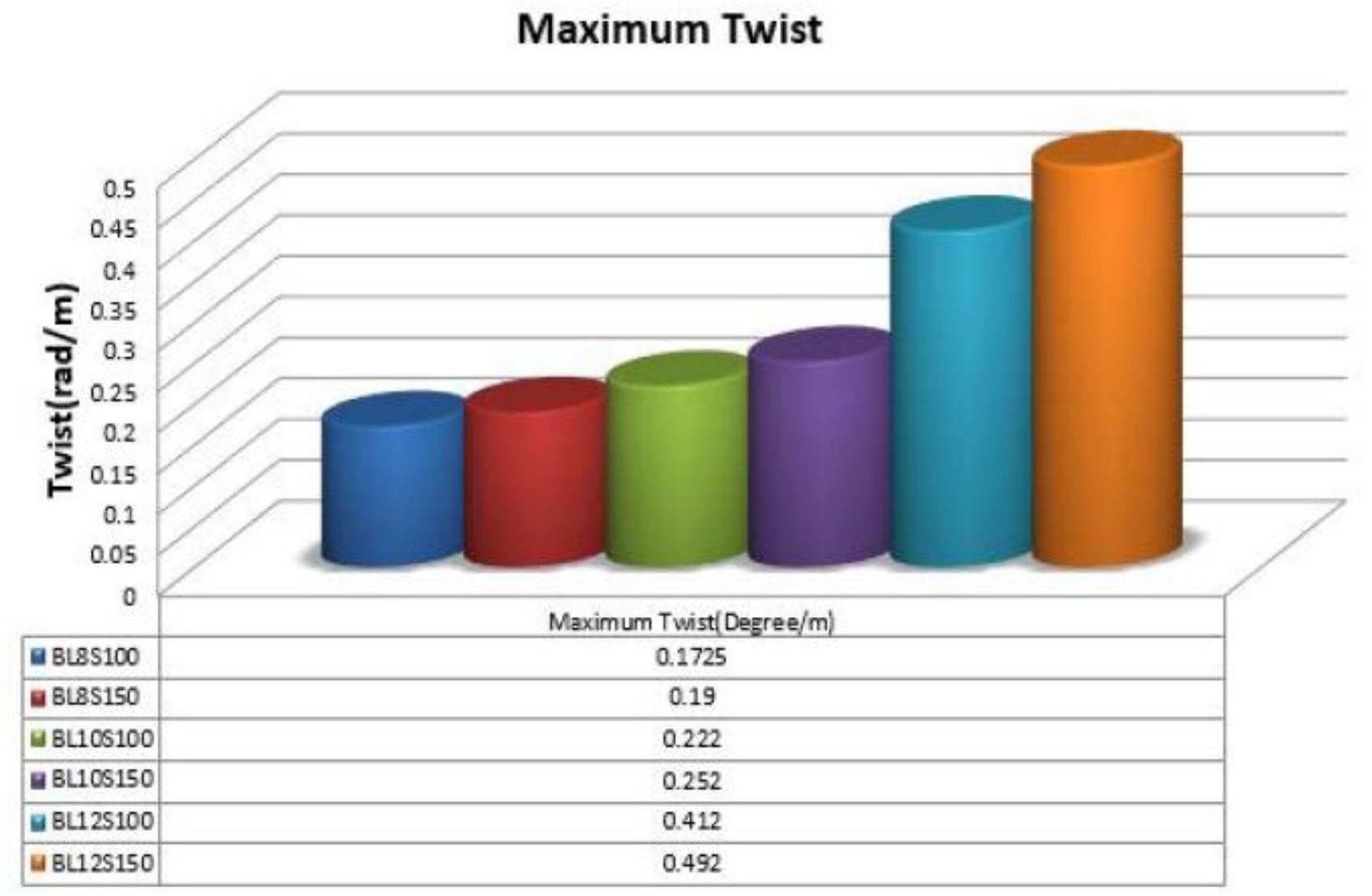

Fig 3: Specimen v/s Maximum Twist

From Figure 2 can be concluded that the torque is not much affected by lateral as well as longitudinal reinforcement of beam before creaking and only depends on the grade of concrete and immediately after cracking only steel is effective for resisting the torque. It is concluded that as the stirrups spacing increases the torsional flexibility of beam increases for the same longitudinal steel. It is also observed that optimum spacing of lateral reinforcement is an equally important.

\section{Total Energy Dissipation}

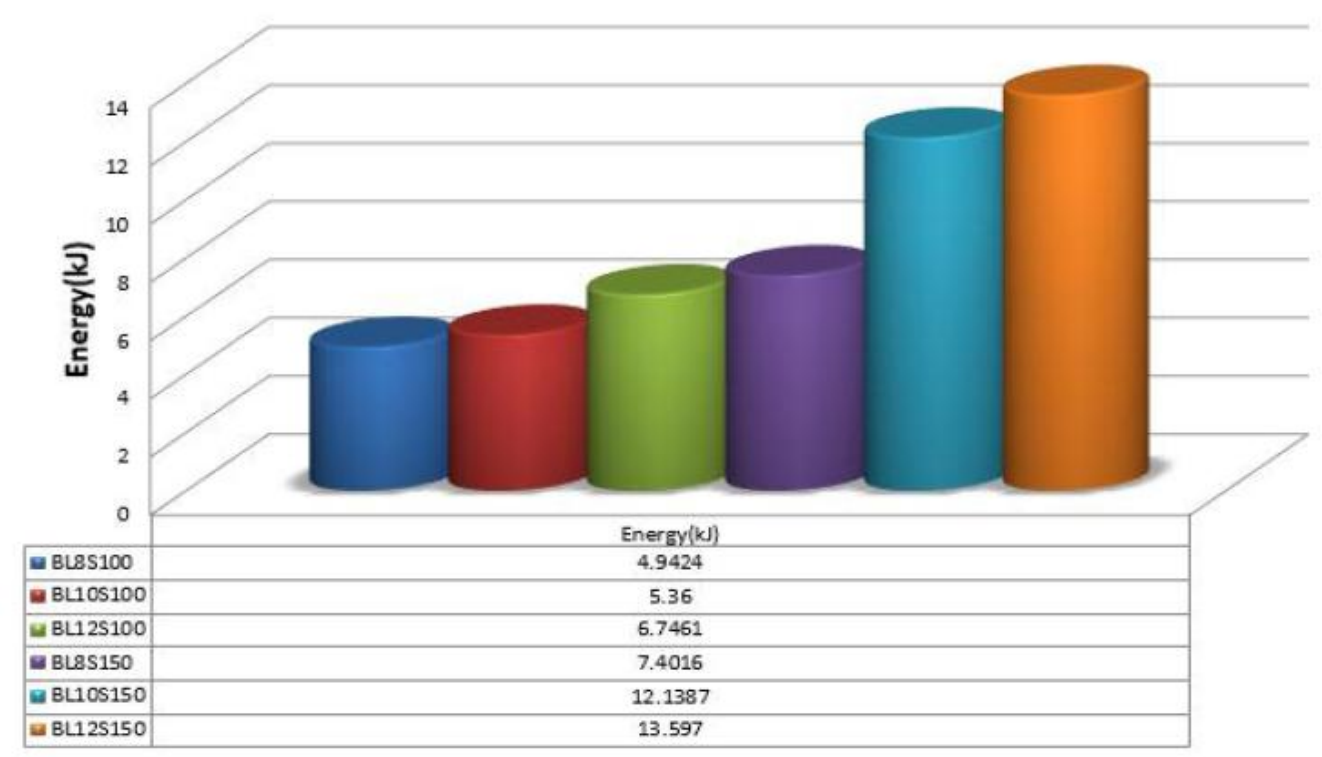


Fig 4: Specimen v/s Total Energy Dissipation
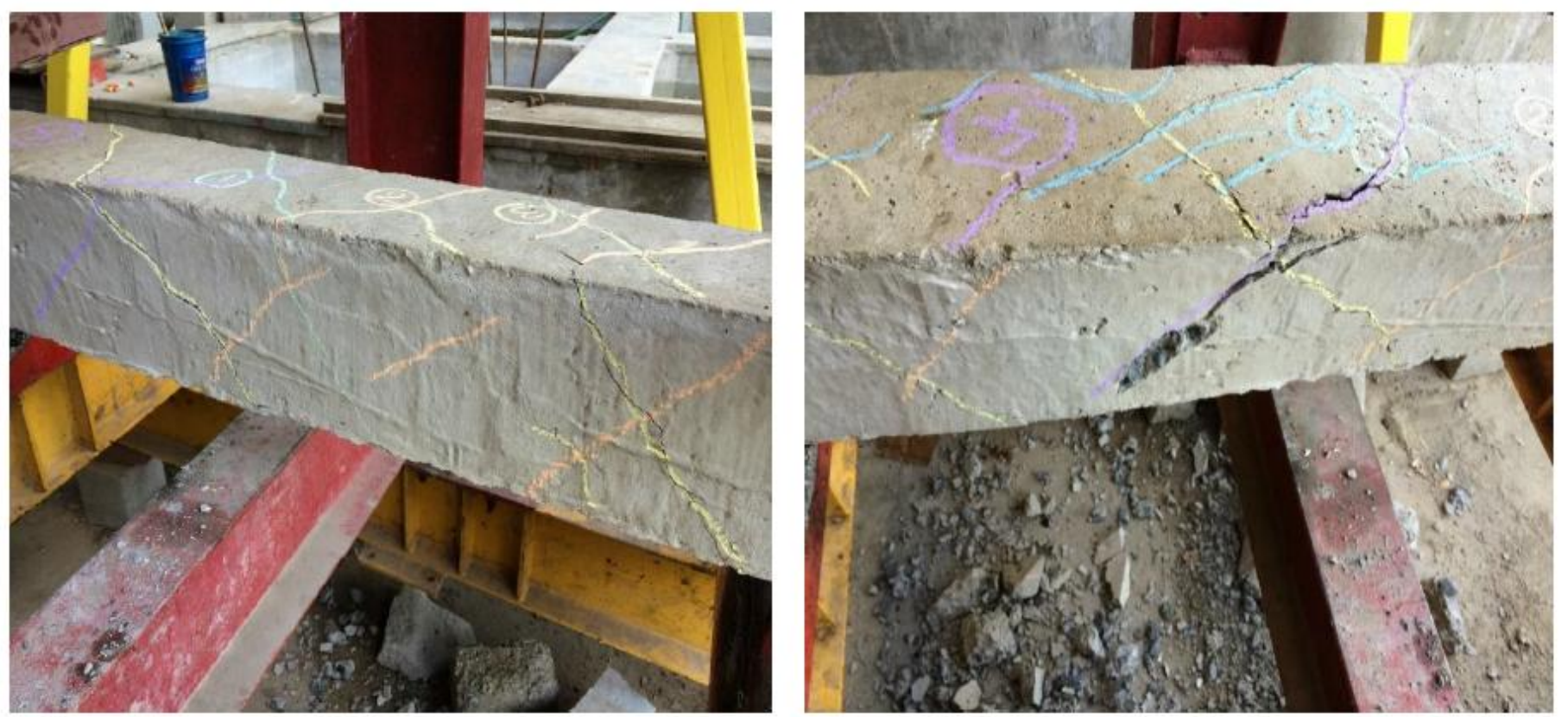

(a) Cracking Pattern in Beams

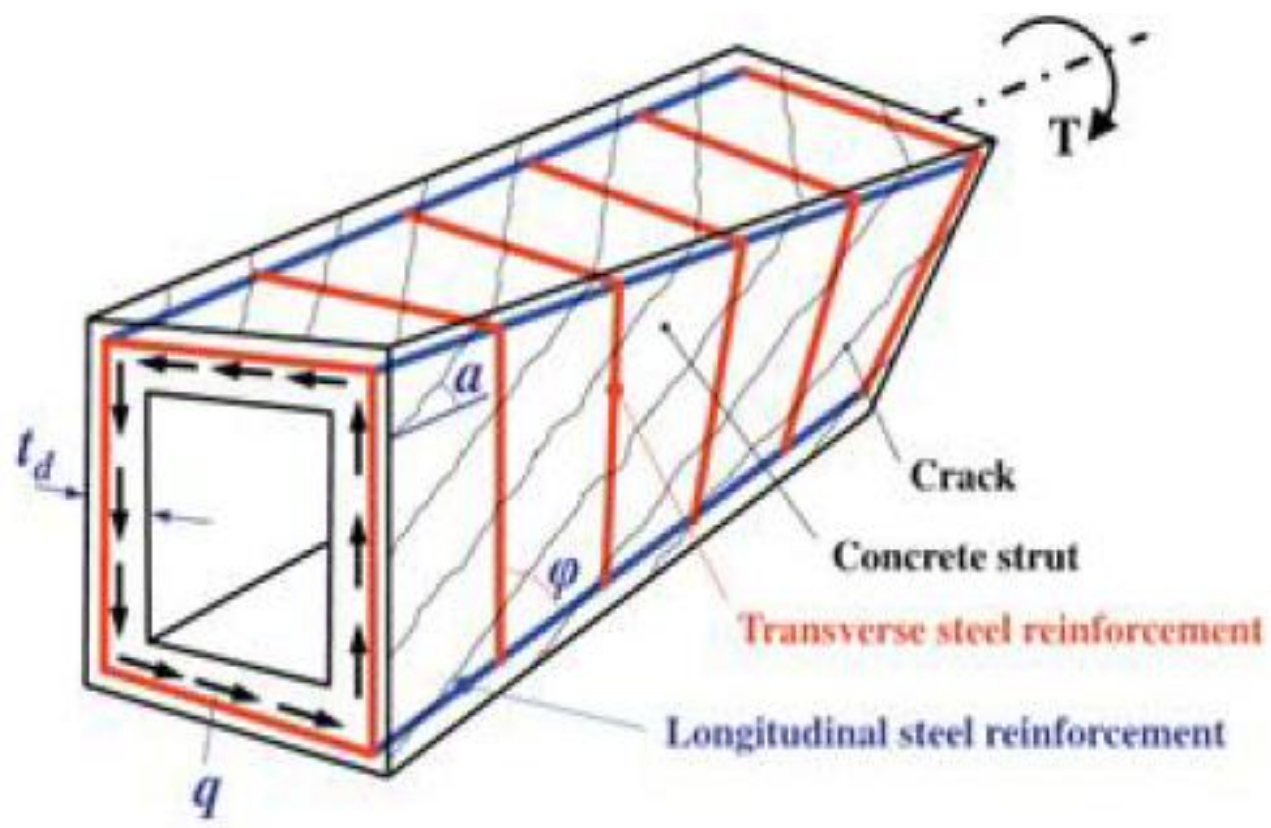

(b) Space Truss components of a RCC beam under torsion [4]

Fig 5: Creaking Pattern in Beams

From Figure 4, the range of increase in energy dissipation for the same amount of longitudinal rein-forcement and different transverse reinforcement of $100 \mathrm{~mm}$ and $150 \mathrm{~mm}$ spacing is from $8.45 \%$ to $12.01 \%$. It was observed during test that energy dissipation less during $1^{\text {st }}$ and $2^{\text {nd }}$ cycle due to just started crack in concrete. From Figure 5, it was observed that most probable first crack was observed at the angle of $42^{\circ}$ to $45^{\circ}$ to the bottom of the beam. It was also observed the cracking of concrete was in manner of small concrete struts as seen in space truss analogy and cracks were meeting at nearly right angle to each other.

\section{CONCLUSION}

Cracking Torque in all six beams BL8S100, BL10S100, BL12S100, BL8S150, BL10S150, and BL12S150 was observed to be almost same that means steel does not affect the cracking torque and it only depends on the grade of concrete. All six beams BL8S100, BL10S100, BL12S100, BL8S150, BL10S150, and BL12S150 were cracked at par torsional moment. At full cracked condition the elon-gation and buckling of main steel was observed but the stirrups 
were intact with minor defor-mation that means at ultimate stage the main reinforcement alone resist the torsional moment. In all type of beams having stirrups @ $150 \mathrm{~mm} \mathrm{c/c}$ exhibited more energy dissipation compared to beams having stirrups@100 mm c/c. It implies that the shear reinforcement affects the torsional capacity of RC hollow beam under pure cyclic torsion. In all type of beams having stirrups@100 mm c/c exhibited less twist compared to beams having stirrups@150 mm c/c. It shows that the shear reinforcement does not affect the torsional flexibility of the $\mathrm{RC}$ hollow beam under pure cyclic torsion and depends on longitudinal reinforcement only. Energy dissipation range for same longitudinal steel and different spacing is less than the same transverse reinforcement and different longitudinal rein-forcement. Main reinforcement is more influencing in torsional behaviour of RC hollow beam under pure cyclic torsion then shear reinforcement. Post-cracking behaviour of RC hollow beams under pure cyclic torsion is purely governed by longitudinal and shear reinforcement.

\section{ACKNOWLEDGEMENTS}

The authors are thankful to Civil Engineering Department, Institute of Technology, Nirma University, Ahmedabad to carry out the project.

\section{REFERENCES}

[1] Khaldoun, N. R., "Torsion strength of reinforced concrete beams", Canadian Journal of Civil Engineering, V. 27, 2000, pp. 445-453.

[2] Khaldoun, N.R., "Torsional strength of normal and high strength reinforced concrete beams", Engineering Structures, V. 56, 2013, pp. 2206-2216.

[3] Deifalla, A., "Effectiveness of externally bonded CFRP strips for strengthening flanged beams under torsion: An experimental study", Engineering Structures, V. 56, 2013, pp. 2065-2075.

[4] Constantin, E., Chris, G.K., "Experimental Investigation on RC beam with rectangular spiral reinforcement in Torsion', Engineering Structures, V.56, 2013, pp. 286-297.

[5] Patel, P.V., Purohit, S., Jariwala, V., "Strengthening of RC beam subjected to combined tor-sion and bending with GFRP composite", Procedia Engineering, V.51, 2013, pp. 282-289.

[6] Faud, O., Serkan, E., "Torsional Behaviour of steel fiber concrete beams", Construction and building material, V.28, 2012, pp.269-275.

[7] Lopes, S.M.R., Bernardo, L.F.A., "Torsion in Reinforced High Strength Concrete Hollow Beams", Icons 2005, International Conference for Structures: $01 / 2015$.

[8] Velpulla, V., Pandit, G. S., "Cyclic Torsion Test on Reinforced Concrete Beams", Journal of Structural Engineering, V. 113, 1987, pp. 1329 - 1340. 